India's experience are valuable for other developing WTO Members, in terms of building capacity, identifying the policy space a government needs as well as the interests worth pursuing through WTO DS, and strategizing and co-ordinating with commercial and other stakeholders. Last but not least, it was fascinating to be reminded of the origins of the interpretation of basic concepts both in substantive and procedural WTO law in many of the cases that India was involved in. Even for readers not intimately familiar with details of WTO jurisprudence, the well-written and in-depth analysis in this volume elucidates clearly the many interesting interpretative questions addressed by WTO adjudicative bodies in disputes involving India.

MARIA KoTsi, European Commission, Brussels ${ }^{1}$

1 These are the reviewer's views and do not necessarily reflect the views of the European Commission.

doi:10.1017/S1474745617000076

\title{
International Economic Law after the Global Crisis: A Tale of Fragmented \\ Disciplines \\ by S.L. Lim and Bryan Mercurio \\ Cambridge: Cambridge University Press, 2015
}

This is an ambitious compendium of 20 articles exploring the 'fragmented nature of international economic law'. It covers monetary cooperation, trade and finance; investment law and intellectual property protection; and climate change regulation in the aftermath of the 2008 financial crisis.

The introductory article sets out twin concerns about multiplication of disciplines and tribunals, norm fragmentation, and authority fragmentation. The authors set the stage by looking at the history of international economic regulation since the Bretton Woods system to find out how what was initially conceived of as an 'integrated or cohesive system of global regulation' ended up in the current fragmented state.

Weber provides an overview of the 'fragmentation of legal sources' in the field of international financial regulation. He tackles what he calls 'the hard law v. soft law controversy'. He contrasts the 'robust', 'hard law' framework of the WTO and the IMF/ World Bank with informal law-making, sometimes by 'inter-agency institutions with ambiguous legal status', in the field of international financial law. The article supports 'multilayered governance': 'By means of standard-setting, the different layers of governance must be dynamically interlinked to enable them to address developments in the ever-evolving financial markets.'

Cervone's focus is on credit rating agencies (CRAs). Since the financial crisis, CRAs have come under closer scrutiny, both because of their alleged roles in the events leading up to the financial crisis, and, since 2010, in respect of the sovereign debt issue, and because of the increasing integration of CRAs into the regulatory fabric of financial transactions. New EU regulations have certification and endorsement provisions that 'could have considerable extraterritorial implications' as a global regulatory strategy.

The regulation of CRAs is only one response to the variegated crises that engulfed financial markets after 2007. What Avgouleas and Arner describe as the 'near collapse of national financial systems' in the Eurozone is not given to evident diagnoses, let alone 
solutions. Their article is a comprehensive examination of the EU financial market from its early days to the emergence of the European Banking Union.

From regional fragmentation to coherence, Buckley sees it as a way forward for East Asia. Noting the multitude ways in which the countries in the region differ from one another, the author concludes that 'East Asia is naturally a fragmented, not a cohesive region.' This fragmentation is one of at least four reasons why 'the region' has had little impact on global economic governance.

Lim notes 'the long-standing controversy over the Chinese yuan': China keeps the $\mathrm{RMB}$ at an artificially low rate to increase exports and limit imports; the active intervention in the market also results in exaggerated foreign reserves. The 'controversy' lies in the interplay between pursuing a legitimate domestic policy and 'currency manipulation' with the objective of affecting trade. Lim concludes by arguing that, 'if global anti-dumping rules allow for trade remedy action against China, then the conventional political-morality of the GATT-WTO also supports it'.

Hertogen examines the potential for externalities arising out of limited international discipline on sovereign action in monetary policy and how this is exacerbated by 'limitations in trade liberalization agreements on states' ability to regulate financial services offered within their territory', and encourages members to seek a reinterpretation of WTO disciplines through active dispute settlement.

Nakagawa's starting point is that 'under the current WTO law, a new member ... must redesign its development and/or transition strategy within the contracted policy space according to WTO law'. For historical, theoretical, and practical reasons, this apparent contraction of policy space is not detrimental to social and economic development; arguments that seek to carve out development exceptions in trade law should be dismissed because they result in 'sterile fragmentation between international trade law and international development law'.

Broude and Hestermeyer note 'complex links' between trade law and human rights law because:

When economic operators trade internationally, not only goods and services cross national boundaries, but also the culture, opinions, information, and ideas that they carry.

The authors observe that trade law and human rights law offer 'divergent rationales' with respect to freedom of speech. Whereas trade law views free speech in purely utilitarian terms, human rights law starts from the perspective of the 'inherent dignity of the human person'. Hence, 'weak support for a conceptual confluence between liberal trade and the human right of free speech'.

Peng identifies 'excess disciplinary fragmentation' within the WTO itself. The article is a comprehensive examination of emergency safeguards measures (ESM) in the context of services, covering the current negotiations in the WTO as well as examples in various regional trade agreements.

After examining the countermeasure regimes of both the WTO and the Asean Comprehensive Investment Agreement, Paparinskins notes that 'the situation where WTO-authorized conduct cannot be exercised due to investment protection obligations suggests the possible presence of a conflict'. Possible, in that it would depend on how 
'conflict' is defined or resolved, which analysis raises 'broader theoretical questions about the nature and operation of the international legal order'.

Krug tracks the convergence of investment fund regulation since the financial crisis. While regulatory approaches have been different, the 'common thread among these regulatory reforms has been a general concern with both systemic risk mitigation and heightened protection of investors'. The question is how convergent are these regulations and whether such convergence is desirable or effective.

Bolstering global investment activity might well be a desirable objective; Chaisse examines the case of when such activity runs into the headlong winds of financial crisis management. Greece's 2012 sovereign debt restructuring was the largest in history; in the aftermath of the Abaclat decision, the class action launched by Greek bondholders was not unexpected. The article that follows is also a close examination of specific obligations of one country - China - under its various investment treaties, in the light of 'the "fragmentation" of investment law'.

Martin zooms out by at least an order of magnitude to look at foreign direct investment and agriculture. The concern arises because host states 'seem unable to regulate' foreign direct investment in land development and, in particular, its 'widely documented controversial impact on populations and the environment'. Quoting The Economist and Korea Times, the article concludes by expressing concern about 'colonialism'.

Voon, Mitchell, and Munro tackle investor rights and investment agreements, this time in relation to intellectual property rights, by using the Philip Morris arbitration as a case study. The authors examine in what way intellectual property may fall within investment treaties, in subject/variable terms and in objective/fixed terms. They then examine the applicable investment law disciplines.

Mercurio notes that the field of international intellectual property law is among the most fragmented areas of international economic law. The Anti-Counterfeiting Trade Agreement (ACTA) further fragments the system. The article argues that 'the ACTA is a failed agreement ... because the final text does not meet the aims and objectives set out by the negotiating countries'.

Bartels examines the WTO-consistency of applying the EU's emissions trading system to aviation against the broader context of the scheme's differentiated economic impact and parallel efforts at addressing the issue in other international fora. He examines the failed negotiations in the International Civil Aviation Organization (ICAO). He then looks at the EU measure in the context of both the goods and the services disciplines of the WTO. He notes 'the fact' that compliance with international obligations will not be grounds for justification under the general exceptions to the GATT and the GATS.

Leal-Arcas and Filis take issue with referring to an 'international community' when instead we are dealing with 'a collection of sovereign entities that, while formally enjoying the legal equality flowing from their sovereign status, in reality, are as highly disparate among themselves as their interests'. The article concludes that the WTO system 'could, and does, accommodate bona fide non-discriminatory measures that promote the scale-up and take-up of renewable energy'.

'Norm fragmentation', the editors conclude, has been particularly visible in the field of investment law: 'how different norms ... apply to investment-related activities and bilateral relationships due to the absence of a unifying, global treaty in the field of investment regulation'. This is one aspect of norm fragmentation. The authors then 
turn to 'trans-substantive' authority fragmentation: 'Different international institutions coexist on the global plane.' They observe that 'there is no overall design to guide us in organizing the fragments of the international economic order'.

I note at least four challenges with this volume.

First, there is much valuable research and some interesting analysis in various articles; and yet, to get to these, the reader has to pass through sentences such as the following:

informal lawmaking leads to more extensive capacity-building: its enabling functionality in financial markets serves the facilitation of the coordination process while at the same time providing directionality to the provision of cross-border standards; an informal lawmaking quality allows the regulators to enter into agreements by varying scope and specificity and then to clarify (or change) the expectations of the concerned parties.

There are other instances of similarly prolix constructions sprinkled throughout the book - not so much as to drown it, but enough to give pause to even a seasoned practitioner of trade law and financial institution regulation. Added to this is the occasional conceptual confusion. As Cervone explains it, the EU regulation applies to foreign CRAs only when they issue ratings for 'bonds issues in the EU market' or when the ratings are used by 'banking institutions in the EU for risk weight assessment'. Merely because the issuer is foreign-based, however, the application of regulations in respect of activities in the EU does not strike me as particularly 'extraterritorial'. Then there is Bartels' 'surprising ... fact' that the 'rule' in Brazil-Tyres would prevent recourse, in other cases, to 'international obligations' as justification under Article XX - an assessment, sound if overbroad, but hardly a 'fact'; or Lim's application of 'the conventional political-morality of the GATTWTO' to anti-dumping disputes; a novel concept, to say the least. At a minimum, the editors needed to do closer editing.

Second, the ambition of the volume gives rise to lack of coherence - ironic in a book lamenting lack of coherence. The editors make little attempt to link either climate change or intellectual property law and the 'global crisis'. To the extent that the disciplines fall within the book's subtitle, scant space is devoted to explaining that the nature of 'fragmentation' in the fields of climate change and intellectual property is different from that in international financial regulation. This does not detract from the excellence or usefulness of the articles, only that juxtaposing them alongside others that are at least connected in some way to the global financial crisis risks a measure of incongruence.

Third, 535 pages into the volume, and it was not still entirely clear to this reader what the problem was with 'fragmentation'. Not so much that the specific issues arising out of fragmentation - however defined - are not challenging, but that what is the real alternative that could or would give rise to better actual results, or could or would have avoided problems we are facing today? The opposite of fragmentation is not mere coherence, but - as the editors expressly state - unification. What do we do? 'Unify' all 3, $\overline{000 \text { invest- }}$ ment treaties; then bring investment, trade, climate change, the environment and human rights law under one unfragmented treaty and institution ... and then 'hard' law obligations in respect of financial regulation ... how transparent, comprehensible or coherent do we expect this beast of a treaty to be? Which behemoth of a multilateral secretariat 
will manage it? What leviathan of an international court will make sense of it? And even if we are not to go that far, how could a simple 'overall design' address the myriad challenges of competing priorities and interests that arise as soon as one descends from 'design' into operational details? 'Fragmentation' has arisen organically over three centuries of international law development and in response to real problems in the context of concrete interests of states and other actors in the international arena; the answer cannot be clamoring for a bureaucratic monster. The practicalities and desirability of unfragmentation to one side, the editors do not seem to believe in the premise of their own thesis. They assert that, 'we have lost the coherence and overarching design of a now bygone era of global economic management'; but then they concede that 'the design at Bretton Woods never worked as intended' - a bygone era that never existed; 'global economic management' that never worked as intended ... then what?

Finally, in a volume on international economic law and the global crisis, the sole article touching upon global regulatory fragmentation is uninspiring; even with the companion regional pieces, the sum of the parts does not add up to a coherent whole. At the heart of Weber's article is what he calls the 'hard law-soft law' controversy. The parameters are not clear - 'soft law' is sometimes described as rules emanating from government networks, other times as private rules - but the central thesis is clear: 'overcoming the dichotomy of hard law and soft law should be an important objective in international financial regulation'. Nothing could be further from the minds of financial market regulators and prudential supervisory authorities, whose 'important' objectives are, and ought to be, avoiding another global financial crisis, protecting consumers, and ensuring healthy competition.

National regulators and financial supervisors belong to the same governments that negotiate multilateral treaties and set up international organizations and courts of varying degrees of effectiveness. Those governments are neither shy about nor ignorant of 'hard law'; they have demonstrated themselves to be quite capable of overcoming the dichotomy where, in their view, it has been necessary. Nor is it useful to ascribe the reluctance of states to engage international legal instruments in the field of financial regulation to bureaucratic jealousy - similar jealousies exist in other fields, and have been resolved. Finally, financial services trade is, for the most part, already subject to multilateral trade rules.

The question is, rather, whether global prudential regulation and supervision is more effective through detailed, internationally negotiated legal obligation or rather principles and targets arrived at on the basis of periodic exchanges of best practices; whether the proper way to resolve disagreements on the reasonableness of prudential measures in a given circumstance is through binding arbitration on the basis of legal submissions, or compliance-centred peer-review; and whether an international legal order that acknowledges the complexity of the modern world through specialization whether of norms or of institutions - flexibility and subsidiarity should be lamented as a 'fragmented' one. In respect of international economic law following the global crisis, this volume does not help in finding an answer to these questions.

RAmbod Behboodi, Rules Division, World Trade Organization, Geneva ${ }^{1}$

1 These are the views of the reviewer and do not necessarily reflect the views of the WTO. 